\title{
Cultivo orgânico de cultivares de cebola nas condições da Baixada Fluminense
}

\author{
Marta SF Ricci $^{1}$; Fernanda FD Almeida ${ }^{1}$; José GM Guerra ${ }^{1}$; David G Cocheto Junior ${ }^{1}$; Raul LD Ribeiro ${ }^{2}$ \\ 'Embrapa Agrobiologia, C. Postal 74505, 23890-000 Seropédica-RJ; marta.ricci@embrapa.br; jose.guerra@embrapa.br; fernandadelga@, \\ yahoo.com.br; davidgoronci@hotmail.com; ²UFRRJ, Ladeira da Meteorologia, 03, 23890-000 Seropédica-RJ; raulucena@gmail.com
}

\begin{abstract}
RESUMO
Com o objetivo de avaliar o desempenho agronômico e a produtividade de cultivares de cebola em cultivo orgânico nas condições da Baixada Fluminense-RJ, foi conduzido um experimento no período de junho a outubro de 2010, no município de Seropédica-RJ. Foram avaliados os caracteres em 10 cultivares de cebola. O delineamento experimental foi em blocos ao acaso com quatro repetições. Avaliou-se as produtividades total, comercial e não comercial, bem como a classificação das cebolas. A produtividade total de bulbos variou de 14,42 a 24,09 $\mathrm{t} \mathrm{ha}^{-1}$, enquanto a produtividade comercial oscilou entre 14,28 a 24,09 $\mathrm{t} \mathrm{ha}^{-1}$. As cultivares mais produtivas e que podem ser recomendadas, foram a Alfa Tropical, Alfa São Francisco, Baia Periforme, Madrugada, Primavera, Jubileu, Pêra Norte e Lola; enquanto as cultivares menos produtivas foram a Vale Ouro IPA 11 e Franciscana IPA 10. A produção de bulbos considerados 'refugo' foi muita baixa, sendo que as cultivares Alfa Tropical, Alfa São Francisco e Lola não produziram essa classe de bulbos. O peso médio de bulbos variou de 54,1-90,3 g, sendo as cultivares Franciscana IPA 10 e Vale Ouro IPA 11, as que apresentaram os menores valores para esse caráter. Os resultados mostraram que o cultivo orgânico da cebola nas condições da Baixada Fluminense é viável, podendo ser obtidas produtividades semelhantes às obtidas no cultivo convencional.
\end{abstract}

Palavras-chave: Allium cepa, agricultura orgânica, caracteres agronômicos, produtividade, mancha- púrpura.

\begin{abstract}
Organic cultivation of onion cultivars in the conditions of the Lowlands of Rio de Janeiro state, Brazil

The agronomic performance and yield of onion cultivars was evaluated on organic farming conditions in the Lowlands of Rio de Janeiro state, Brazil, also named Baixada Fluminense, from June to October 2010, in the municipality of Seropédica. The statistical design consisted of 10 treatments arranged in a randomized block design with four replications. We evaluated the total yield, the marketable and the unmarketable, as well as the classification of onions. The total yield of bulbs ranged from 14.42 to $24.09 \mathrm{t} \mathrm{ha}^{-1}$, while marketable yield ranged from 14.28 to $24.09 \mathrm{t} \mathrm{ha}^{-1}$. The highest yielding cultivars which can be recommended were Alfa Tropical, Alfa São Francisco, Baia Periforme, Madrugada, Primavera, Jubileu, Pêra Norte and Lola; while the lowest yielding cultivars were the Vale Ouro IPA 11 and the Franciscana IPA 10. The production of 'refused' bulbs was very low, and the cultivars Alfa Tropical, Alfa and Lola did not produce this kind of bulbs. The average weight of bulbs ranged from 54.1 to $90.3 \mathrm{~g}$, and the cultivars Franciscana IPA 10 and Vale Ouro IPA 11 were those with the lowest values of 'refused' bulbs. Organic farming of onions in the studied conditions (Baixada Fluminense) is possible and capable of produce yields similar to those obtained in conventional farming.
\end{abstract}

Keywords: Allium cepa, organic agriculture, agronomic characters, productivity, purple blotch.

\section{(Recebido para publicação em 21 de dezembro de 2012; aceito em 6 de fevereiro de 2014) (Received on December 21, 2012; accepted on February 6, 2014)}

$\mathrm{D}$ e acordo com Boiteux \& Melo (2004), das várias espécies cultivadas do gênero Allium, a cebola (Allium cepa), é a de maior destaque em termos de volume de produção mundial ocupando o segundo lugar em valor econômico.

No Brasil, a cebolicultura é uma atividade realizada primordialmente por pequenos produtores e apresenta importância socioeconômica devido à grande demanda de mão-de-obra, possibilitando a fixação de agricultores no campo (Costa et al., 2002).

Os três maiores produtores brasileiros em termos de área cultivada são, em ordem decrescente, os estados de Santa Catarina, Bahia e Rio Grande do Sul, de acordo com dados do IBGE (2010), os quais detêm produtividades de 25,34; 23,47 e $16,19 \mathrm{t} \mathrm{ha}^{-1}$, respectivamente.

O cultivo de cebola orgânica vem aumentando devido à expansão da demanda dos consumidores, possivelmente devido ao aumento da população e aumento da renda dos consumidores. Todavia, para tornar o sistema de produção orgânico de cebola viável, os produtores encontram algumas limitações, das quais as mais relevantes são a carência de fertilizantes orgânicos que forneçam os nutrientes necessários ao crescimento das plantas, o controle de espécies invasoras, o controle fitossanitário e a carência de cultivares adaptadas às condições edafoclimáticas das distintas regiões (Wordell Filho et al.,
2006; Gonçalves et al., 2008; Vidigal et al., 2010). Segundo Gonçalves \& Wamser (2007), a produção de cebola orgânica, quando comparada com o cultivo convencional, atinge níveis de produtividade semelhantes, com menor uso de insumos e menor custo de produção, porém, com maior necessidade de mão-de-obra devido à realização de capinas manuais.

Dentre as características levadas em consideração para classificar as cebolas, estão as exigências fotoperiódicas, o padrão genético, a preferência e a forma de consumo (Oliveira et al., 2004). A cultivar a ser plantada deve ser escolhida em função das condições climáticas da região e da exigência do mercado com 
relação ao tipo de bulbo (Costa et al., 2002).

Costa et al. (2008) avaliaram o desempenho de diferentes cultivares de cebola em sistema orgânico nas condições edafoclimáticas do Vale do São Francisco, e obtiveram produtividades comerciais superiores a 26 e $17 \mathrm{t} \mathrm{ha}^{-1}$, respectivamente em um Argissolo e um Vertissolo, sendo as cultivares Brisa IPA-12, São Paulo, Botucatu-150, Pira Ouro (Argissolo), Texas Grano PRR e IPA-10 (Vertissolo) as mais produtivas.

Ao avaliaram seis cultivares de cebola sob manejo orgânico, na região metropolitana do estado do Rio de Janeiro, Paula et al. $(2003,2005)$ observaram que todas produziram alta proporção de bulbos com boa aceitação comercial, indicando que a região apresenta grande potencial para o cultivo de cebola orgânica.

Vidigal et al. (2010), pesquisaram o desempenho da cultivar CNPH 6400 em sistema orgânico, submetida a doses de composto orgânico à base de dejetos sólidos de suínos em Oratórios, Zona da Mata de Minas Gerais, de maio a outubro de 2005; concluíram que é possível cultivar cebola com boas características produtivas e nutricionais em sistema orgânico. Em contrapartida, Rodrigues et al. (2006), avaliando 16 genótipos de cebola no município de Viçosa, Zona da Mata, Minas Gerais, nos sistemas orgânico e convencional, concluíram que as cebolas obtidas no sistema convencional apresentaram maior peso de bulbos mais adequados à indústria, quando comparados aos bulbos obtidos no sistema orgânico.

Em termos de sanidade da cultura, uma das principais doenças da cebola em regiões de clima tropical e subtropical é a mancha-púrpura ou crestamento, causada pelo fungo Alternaria porri, capaz de gerar perdas de 50-100\% em plantações com cultivares suscetíveis e condições ambientais favoráveis. A umidade é a condição ambiental mais importante para o surgimento da doença, pois o fungo é dependente de água para a germinação do esporo e para a esporulação na superfície da planta (Reis \& Henz, 2009). Nesse sentido, a identificação de cultivares tolerantes à mancha púrpura vai ao encontro das demandas da agricultura orgânica.

O objetivo deste trabalho foi avaliar o desempenho agronômico de cultivares de cebola em cultivo orgânico, buscando identificar aquelas mais produtivas e tolerantes à mancha púrpura e, portanto, as mais promissoras para este tipo de cultivo na região da Baixada Fluminense.

\section{MATERIAL E MÉTODOS}

O experimento foi conduzido no período de junho a outubro de 2010, na área do Sistema Integrado de Produção Agroecológica, conhecida como "Fazendinha Agroecológica km 47”, localizada no município de Seropédica-RJ (22 $45^{\prime} \mathrm{S}$; 43⒋ $41^{\prime} \mathrm{O}, 33 \mathrm{~m}$ de altitude), sendo o clima do tipo Aw segundo a classificação de Köppen, apresentando verões úmidos e invernos secos. A temperatura média anual é de $24,6^{\circ} \mathrm{C}$ e a precipitação média de $1.300 \mathrm{~mm}$, sendo os meses de julho e agosto os mais secos.

O solo da área experimental está classificado como um Planossolo e apresentou as seguintes características químicas na camada de 0 a $20 \mathrm{~cm}$, após a análise realizada seguindo a metodologia da Embrapa (1997): pH em água $=5,4 ; \mathrm{Al}^{3+}=0,0 \mathrm{cmol}_{\mathrm{c}} \mathrm{dm}^{-3} ; \mathrm{Ca}^{2+}=1,4$ $\mathrm{cmol}_{\mathrm{c}} \mathrm{dm}^{-3} ; \mathrm{Mg}^{2+}=0,3 \mathrm{cmol}_{\mathrm{c}} \mathrm{dm}^{-3} ; \mathrm{P}$ disponível $=37 \mathrm{mg} \mathrm{dm}^{-3} ; \mathrm{K}^{+}=94 \mathrm{mg} \mathrm{dm}^{-3}$.

Foram avaliadas 10 cultivares de cebola em delineamento de blocos ao acaso com quatro repetições. As cultivares de cebola avaliadas apresentam as seguintes características: 1) IPA-11 (Vale Ouro), bulbos de formato globoso, cor amarela, ciclo de 130 dias, boa resistência ao transporte, excelente aceitação comercial, elevada resistência a doenças e tolerância ao tripes; 2) IPA-10 (Franciscana), bulbos de formato globuloso achatado, cor roxoavermelhada, ciclo de 85 dias, elevada resistência ao mal-de-sete-voltas e à mancha púrpura (Alternaria porri), moderada tolerância a tripes e boa conservação pós-colheita; 3) Jubileu, bulbos de formato globular alongado, cor amarela, ciclo de 170-230 dias; 4) Primavera, bulbos de formato globular, cor amarela, ciclo de 150-170 dias; 5)
Baia Periforme, cultivar tradicional, bulbos de cor amarelo-clara, formato periforme, muito boa firmeza, ciclo de 170-180 dias; 6) Alfa São Francisco, bulbos de cor amarela, arredondados, firmes e de bom aspecto comercial, ciclo de 120 a 135 dias, recomendada para plantio em condições de temperaturas mais elevadas; 7) Lola, bulbos de cor amarela, formato globular, ciclo de 150-160 dias; rusticidade (cerosidade da folha), boa coloração nos bulbos e alta qualidade da casca, ótima sanidade, firmeza, uniformidade dos bulbos e boa conservação pós-colheita; 8) Alfa Tropical, bulbos de cor amarela, globulares, firmes e de bom aspecto comercial, ciclo de 120 dias; 9) Madrugada, bulbos de formato globular alongado, cor amarela, ciclo de 160-200 dias; 10) Pêra Norte, bulbos de cor amarela, globular com base achatada, ciclo de 180-230 dias.

As parcelas experimentais foram constituídas por canteiros medindo 2,1x1,0 m, sendo a parcela útil constituída pelas 20 plantas posicionadas na área mais central da parcela $\left(0,75 \mathrm{~m}^{2} \mathrm{de}\right.$ área útil). Antes do plantio, as parcelas receberam uma adubação com esterco bovino curtido equivalente à dose de $2,5 \mathrm{~kg} \mathrm{~m}^{-2}$.

As cultivares foram semeadas em bandejas de poliestireno expandido de 200 células preenchidas com substrato orgânico constituído por vermicomposto e, carvão vegetal moído (15\% $\mathrm{v} / \mathrm{v})$ peneirado em malhas de 3 e $5 \mathrm{~mm}$ de abertura e enriquecido com torta de mamona (2\% v/v) (Oliveira, 2011).

O transplantio das mudas para o campo ocorreu 30 dias após a semeadura, no espaçamento de $30 \mathrm{~cm}$ entre linhas e $12,5 \mathrm{~cm}$ entre plantas, colocando-se uma muda em cada cova de plantio.

Transcorridos 15 dias do plantio das mudas, foi realizada uma adubação de cobertura equivalente a $1,5 \mathrm{t} \mathrm{ha}^{-1}$ de torta de mamona ( 5 a $6 \%$ de nitrogênio), ocasião em que foi realizado o desbaste, deixando-se uma planta por cova, restando uma população de aproximadamente 140,5 mil plantas por hectare.

Trinta dias após o transplante foi distribuída uma cobertura morta de folhas provenientes da poda da parte aérea de Gliricidia sepium, aplicada 
na quantidade equivalente a $2,0 \mathrm{~kg}$ de massa fresca por metro quadrado de canteiro. A análise foliar mostrou que esse material contém um teor de $33 \mathrm{~g}$ $\mathrm{kg}^{-1}$ de nitrogênio.

Durante a condução do experimento foram realizadas capinas manuais para manter a cultura livre da competição de plantas invasoras. A irrigação da área experimental foi feita por aspersão, durante todo o ciclo da cultura.

Após 96 dias do transplante avaliou-se a severidade de ocorrência de "mancha púrpura". Foram analisadas individualmente as cebolas que se encontravam dentro da área útil, contabilizando o número de folhas de cada planta sadia contendo manchas da doença, com base nos quais, calculou-se a porcentagem de danos.

A colheita foi realizada 112 dias após o transplante para as cultivares IPA 10, Alfa Tropical, IPA 11, Alfa São Francisco, Lola, Primavera, Pêra Norte, Madrugada e Jubileu quando estavam "estalando" e, aos 126 dias, para Baia Periforme. Durante a colheita, a parte aérea foi separada ainda no campo, sendo levados somente os bulbos para galpão ventilado, no qual permaneceram por um período de sete dias para o procedimento de cura.

As cebolas foram classificadas por diâmetro, conforme a classificação utilizada pela EPAGRI (2000), que considera as seguintes classes: classe 1 (não comercial ou refugo), classe 2 (bulbos com diâmetro entre $35-50 \mathrm{~mm}$ ), classe 3 (bulbos com diâmetro entre 50-60 mm) e classe 4 (bulbos com diâmetro entre 70-90 mm).

Após separadas em classes, o material foi pesado a fim de estimar as produtividades comercial, não comercial (refugo) e total, bem como o peso médio dos bulbos.

Aproximadamente aos 100 dias após o plantio das mudas, avaliou-se a incidência de mancha-púrpura, tomando-se como base 20 plantas por parcela. Em cada planta foram contados o número de folhas total por planta e o número de folhas com a presença do fungo.

Os dados foram submetidos à análise de variância, sendo a significância detectada pelo teste $\mathrm{F}$ a $5 \%$ de probabilidade de erro. As médias foram comparadas por meio do teste Scott-Knott a 5\% de significância. As análises estatísticas foram realizadas com auxílio do programa SISVAR.

\section{RESULTADOS E DISCUSSÃO}

A produtividade das cultivares de cebola incluídas no estudo, em termos de bulbos "curados" de padrão comercial, variou de 14,42 a 24,09 $\mathrm{t} \mathrm{ha}^{-1}$ (média de 20,49 t ha $^{-1}$ ) (Tabela 1$)$, faixa de variação bastante ampla (69\%), sinalizando uma diferença altamente significativa entre as cultivares em função das condições sobretudo climáticas da região, assim como do manejo orgânico empregado. A média geral do rendimento das cultivares em bulbos de padrão comercial foi de 20,14 $\mathrm{tha}^{-1}$, valor que se situa próximo das médias de produtividade da cebola nos estados considerados os maiores produtores brasileiros, Santa Catarina $\left(25,34\right.$ t ha $\left.^{-1}\right)$ e Rio Grande do Sul $(23,47$ $\mathrm{t} \mathrm{ha}^{-1}$ ), de acordo com IBGE (2010).

Paula et al. (2009) também alcançaram média ao redor de $26 \mathrm{t} \mathrm{ha}^{-1}$ na mesma localidade (Seropédica-RJ), utilizando manejo orgânico similar na cultivar de cebola Alfa Tropical, a qual também fez parte do ensaio ora relatado. É possível que os resultados discor- dantes tenham advindo de parâmetros edafoclimáticos variáveis entre os anos e períodos experimentais, enquanto comparações não tenham sido efetuadas a respeito. Pelos valores da Tabela 1, pode-se verificar que as cultivares Alfa Tropical, Alfa São Francisco, Baia Periforme, Madrugada, Primavera, Jubileu, Pêra Norte e Lola foram as mais produtivas quanto ao rendimento de bulbos comercialmente adequados, enquanto as menos produtivas foram a Vale Ouro IPA 11 e a Franciscana IPA 10, as quais constituíram um segundo grupo.

Costa et al. (2008) avaliaram o desempenho produtivo de 18 cultivares de cebola submetidas a manejo orgânico em duas regiões do Vale do São Francisco, dentre as quais, as cultivares IPA 10, IPA 11, Alfa Tropical e Alfa São Francisco, presentemente também avaliadas, obtendo produtividades entre 7,45 e 38,32 $\mathrm{t} \mathrm{ha}^{-1}$, assim constatando a ocorrência de extremos de variação entre cultivares de cebola quando o sistema orgânico é adotado, resultado que, de certa forma, guardadas as devidas proporções, corrobora com os resultados observados no presente estudo.

Valores de produtividade de cebola comparáveis aos obtidos no presente estudo foram alcançados por Gonçalves \& Wamser (2007) em cultivo orgânico

Tabela 1. Produtividades das cultivares de cebola avaliadas sob manejo orgânico, nas condições da Baixada Fluminense (yield of onion cultivars evaluated under organic management, in conditions of Lowlands of Rio de Janeiro state, Brazil). Seropédica, UFRRJ, 2010.

\begin{tabular}{lccc}
\hline \multirow{2}{*}{ Cultivar } & $\begin{array}{c}\text { Peso médio do } \\
\text { bulbo }(\mathbf{g})\end{array}$ & \multicolumn{2}{c}{ Produtividade (t ha $\left.\mathbf{~}^{\mathbf{1}}\right)$} \\
\cline { 2 - 4 } Alfa Tropical & $90,3 \mathrm{a}$ & $24,09 \mathrm{a}$ & $24,09 \mathrm{a}$ \\
Alfa São Francisco & $77,8 \mathrm{a}$ & $20,74 \mathrm{a}$ & $20,74 \mathrm{a}$ \\
Baia Periforme & $81,8 \mathrm{a}$ & $21,82 \mathrm{a}$ & $21,74 \mathrm{a}$ \\
Madrugada & $80,1 \mathrm{a}$ & $21,35 \mathrm{a}$ & $21,07 \mathrm{a}$ \\
Primavera & $87,3 \mathrm{a}$ & $23,27 \mathrm{a}$ & $21,77 \mathrm{a}$ \\
Jubileu & $79,3 \mathrm{a}$ & $21,14 \mathrm{a}$ & $19,83 \mathrm{a}$ \\
Pêra Norte & $76,7 \mathrm{a}$ & $20,46 \mathrm{a}$ & $20,39 \mathrm{a}$ \\
Lola & $76,4 \mathrm{a}$ & $20,36 \mathrm{a}$ & $20,36 \mathrm{a}$ \\
Vale Ouro IPA 11 & $64,8 \mathrm{~b}$ & $17,29 \mathrm{~b}$ & $17,15 \mathrm{~b}$ \\
Franciscana IPA 10 & $54,1 \mathrm{~b}$ & $14,42 \mathrm{~b}$ & $14,28 \mathrm{~b}$ \\
\hline Média & 76,9 & 20,49 & 20,14 \\
CV (\%) & 12,5 & 12,5 & 13,7 \\
\hline
\end{tabular}

Médias seguidas da mesma letra nas colunas não diferem entre si pelo teste de Scott-Knott $(\mathrm{p}<0,05)$ [means followed by the same letter in columns do not differ by Scott-Knott test $(\mathrm{p}<0.05)]$. 


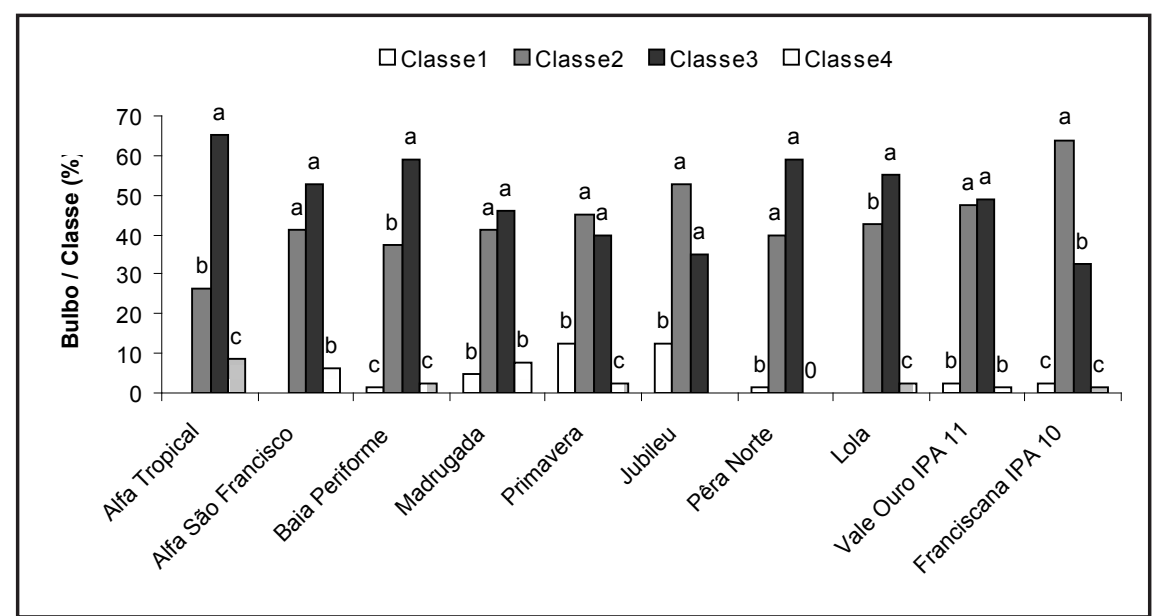

Figura 1. Porcentagem de cada classe de bulbos de cebola por cultivar, obtidas sob o manejo orgânico na Baixada Fluminense (classification of bulbs of onion cultivars obtained under organic management in conditions of Lowlands of Rio de Janeiro state, Brazil). Seropédica, UFRRJ, 2010.

Médias seguidas pela mesma letra, para cada cultivar, não diferem pelo teste Scott-Knott $(\mathrm{p}<0,05)$ [means followed by the same letter, in each cultivar, do not differ by Scott-Knott test $(\mathrm{p}<0.05)]$.

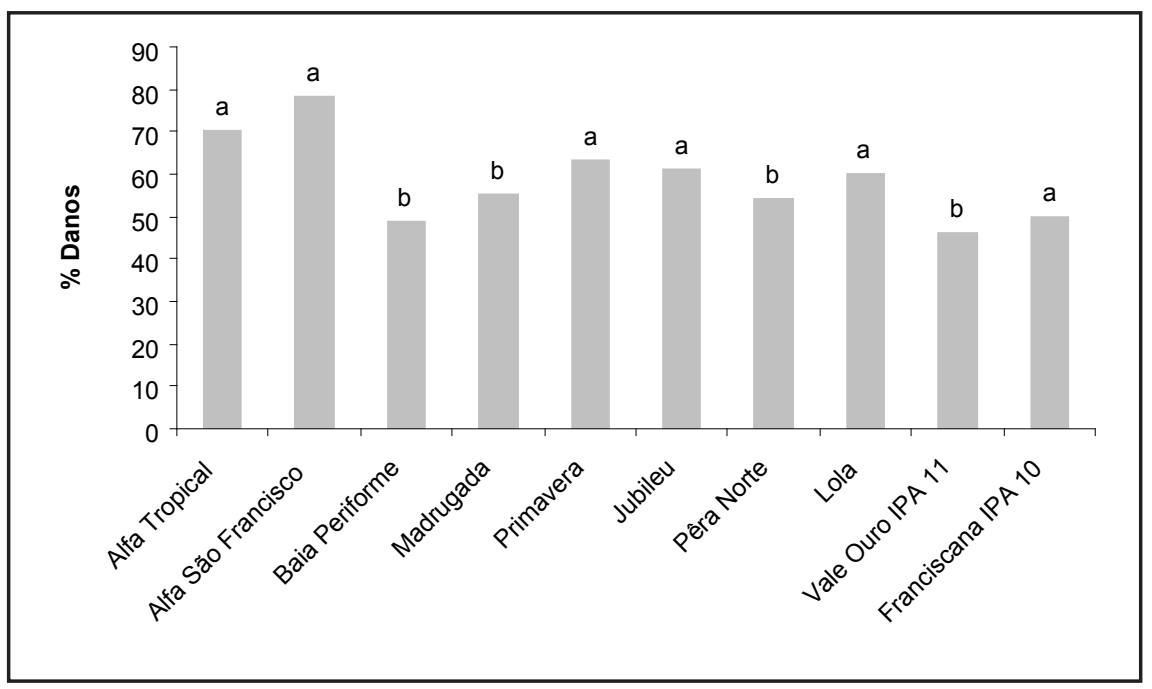

Figura 2. Porcentagem de danos causados pela incidência de Alternaria porri (manchapúrpura) em cultivares de cebola, nas condições de manejo orgânico na Baixada Fluminense (percentage of damage by purple blotch caused by Alternaria porri in onion cultivars, cultivated under organic management in the conditions of Lowlands of Rio de Janeiro state, Brazil). Seropédica, UFRRJ, 2010.

Médias seguidas da mesma letra não diferem entre si pelo teste Scott-Knott $(\mathrm{p}<0,05)[$ means followed by the same letter do not differ by Scott-Knott test $(\mathrm{p}<0.05)]$.

dessa hortaliça, enfatizando que no manejo orgânico a aquisição de insumos é reduzida, porém a demanda de mão-de-obra é maior. Rodrigues et al. (2006), ao avaliarem 16 genótipos de cebola em cultivo orgânico e convencional, em Viçosa-MG, alcançaram produtividades que variaram de 1,83 a $51,85 \mathrm{t} \mathrm{ha}^{-1}$ no sistema convencional e de 6,06 a 50,52 t ha ${ }^{-1}$ no sistema orgânico. $\mathrm{Na}$ opinião $\left(44,23 \mathrm{tha}^{-1}\right)$, resultado que demonstra a importância de selecionar corretamente a cultivar dependendo do tipo de manejo a ser adotado pelo produtor.

Em relação ao peso médio dos bulbos "curados", a faixa de variação foi de 54,1 a 90,3 g, sendo que, também para esta variável, as cultivares Vale Ouro (IPA 11) e Roxa Franciscana (IPA 10), foram as que apresentaram os menores pesos (Tabela 1), diferindo das demais cultivares (Alfa Tropical, Alfa São Francisco, Baia Periforme, Madrugada, Primavera, Jubileu, Pêra Norte e Lola), as quais foram iguais entre si. Rodrigues et al. (2006) avaliaram em sistema orgânico três cultivares incluídas no presente estudo e encontraram valores de peso médio de bulbos de 64,$85 ; 22,25$ e 18,03 $\mathrm{g}$, respectivamente para as cultivares Alfa Tropical, Baia Periforme e Jubileu, todas inferiores àquelas obtidas nas condições de Seropédica. Todas as cultivares produziram bulbos predominantemente inclusos nas classes 2 (diâmetro entre 35 e $50 \mathrm{~mm}$ ) e 3 (diâmetro entre 50 e $60 \mathrm{~mm}$ ), classes essas consideradas de boa aceitação comercial (Figura 1). Resultados semelhantes foram obtidos por Paula et al. (2003) em um estudo realizado na própria Baixada Fluminense, tendo esses autores observado que a maior proporção de bulbos colhidos do cultivo orgânico de "Baia Periforme" foi enquadrada nas classes 2 e 3 .

O percentual dos bulbos considerados como "refugos" foi extremamente reduzido, variando entre 0,08 e 1,49\% (Tabela 1), sendo que as cultivares Alfa Tropical, Alfa São Francisco e Lola não produziram "refugos". Tais resultados são considerados baixos quando comparados aos valores observados por Costa et al. (2008), em cultivo orgânico de cebola na região de Petrolina, Semiárido pernambucano. Esses autores obtiveram percentuais médios de bulbos do tipo "refugo" de 17,89 e $31,58 \%$, respectivamente em estudo de 18 e 14 cultivares de cebola cultivadas em sistema orgânico, sendo o primeiro realizado em um Argissolo e o segundo, em um Vertissolo.

A respeito do nível de incidência e severidade de "mancha púrpura", as cultivares Baia Periforme, Madrugada, Pera Norte e Vale Ouro (IPA11) consti- 
tuíram o grupo menos afetado pelo patógeno, com base na proporção de folhas lesionadas por planta (Figura 2). Deste grupo, somente a cultivar Vale Ouro (IPA 11) apresentou produção comercial significativamente inferior às demais, sinalizando portanto, que a causa principal de queda de rendimento não foi atribuída à doença. Nesse sentido, cabe assinalar que a "mancha púrpura" ocorreu com maior intensidade da metade para o final do ciclo da cebola. Outro fator que pode ter contribuído para este comportamento quase generalizado das cultivares em resposta a essa doença, foi a precocidade da colheita que uniformizou a resposta da cultura em relação ao surgimento da doença, o que não possibilitou diferenciar as cultivares quanto ao nível de tolerância ao patógeno.

Por último, o próprio sistema orgânico de cultivo pode ter representado um condicionante a mais, retardando o surgimento da "mancha púrpura", uma vez que o grau de suscetibilidade da cebola pode estar associado à nutrição mineral da cultura, conforme assinalaram Kurtz \& Ernani (2010).

Os invernos na Baixada Fluminense são comumente pouco rigorosos, na comparação com boa parte das regiões ceboleiras tradicionais do Brasil. Os períodos mais frios do ano são, regra geral, bastante curtos. Por sua vez, a insolação é intensa, embora a duração das noites seja maior em relação a regiões de latitude superior, fatores que possivelmente contribuíram para uma tão expressiva redução no ciclo da cebola, o que já havia sido constatado em pesquisas anteriores realizadas em Seropédica (Paula et al., 2003, 2005).

Os dados obtidos no presente estudo permitem concluir que é viável o cultivo orgânico de cebola durante o inverno na Baixada Fluminense. Das 10 cultivares avaliadas, oito apresentaram produtividades comerciais que variaram entre 20 e $25 \mathrm{t} \mathrm{ha}^{-1}$ (Alfa Tropical, Alfa São Francisco, Baia Periforme, Madrugada, Primavera, Jubileu, Pêra Norte e Lola), sendo que apenas as cultivares Fransciscana IPA 10 e Vale Ouro IPA 11 apresentaram produtividades inferiores a esses valores.

\section{AGRADECIMENTOS}

À Fundação de Amparo à Pesquisa do estado do Rio de Janeiro, pelo financiamento da pesquisa.

\section{REFERÊNCIAS}

BOITEUX LS; MELO PCT. 2004. Sistemas de Produção de Cebola (Allium cepa L). Versão eletrônica. Disponível em: http:// sistemasdeproducao.cnph.embrapa.br/ Acessado em 05 de junho de 2011.

COSTA ND; ARAÚJO JF; SANTOS CAF; RESENDE GM; LIMA MAC. 2008. Desempenho de cultivares de cebola em cultivo orgânico e tipos de solo no Vale do São Francisco. Horticultura Brasileira 26: 476-480.

COSTA ND; LEITE DL; SANTOS CAF; CANDEIA JA; VIDIGAL SM. 2002. Cultivares de cebola. Informe Agropecuário 23: 20-27.

EMBRAPA. 1997. Manual de métodos de análises de solo. 2. ed. Rio de Janeiro: Embrapa Solos. $214 \mathrm{p}$.

EPAGRI. 2000. Sistema de produção para cebola. Florianópolis, 91 p. (Sistema de Produção, 16).

GONÇALVES PAS; BOFF P; ROWE E. 2008. Referenciais tecnológicos para a produção de cebola em sistemas orgânicos. Florianópolis, 21p. (Boletim Técnico, 142).

GONÇALVES PAS; WAMSER GH. 2007. Produção orgânica com agricultores familiares. Revista Brasileira de Agroecologia 2: 63-68.

IBGE. 2010. Produção agrícola municipal: culturas temporárias e permanentes. Rio de Janeiro: IBGE. v. 37

KURTZ C; ERNANI PR. 2010. Produtividade de cebola influenciada pela aplicação de micronutrientes. Revista Brasileira de Ciências do Solo 34: 133-142.

OLIVEIRA EAG. 2011. Desenvolvimento de substratos orgânicos, com base na vermicompostagem, para produção de mudas de hortaliças em cultivo protegido. Seropédica: UFRRJ, 65p. (Dissertação mestrado).

OLIVEIRA VR; LEITE DL; SANTOS CAF; COSTA ND; MELO PCT. 2004. Sistemas de Produção de Cebola (Allium cepa L). Versão eletrônica. Disponível em: http:// sistemasdeproducao.cnph.embrapa.br/ Acessado em 05 de junho de 2011.

PAULA PD; RIBEIRO RLD; GUEDES RE; COELHO RG; GUERRA JGM; ALMEIDA DL. 2003. Época de plantio e desempenho de cultivares de cebola sob manejo orgânico no Estado do Rio de Janeiro. Seropédica: Embrapa Agrobiologia. 4p. (Comunicado Técnico, 60).

PAULA PD; GUERRA JMG; RIBEIRO RLD; CESAR MNZ; GUEDES RE; POLIDORO JC. 2005. Rendimento agronômico do consórcio entre cebola e alface em sistema orgânico de produção. Seropédica: Embrapa Agrobiologia. 4p. (Comunicado Técnico, 74).

PAULA PD; GUERRA JGM; RIBEIRO RLD; CESAR MNZ; GUEDES RE; POLIDORO JC. 2009. Viabilidade agronômica de consórcios entre cebola e alface no sistema orgânico de produção. Horticultura Brasileira 27: 202-206.

REIS A; HENZ GP. 2009. Mancha-púrpura do alho e da cebola: Doença difícil de controlar. Brasília: Embrapa Hortaliças. 6 p. (Comunicado Técnico, 71).

RODRIGUES GB; NAKADA PG; SILVA DJHS; DANTAS GG; SANTOS RRH. 2006. Desempenho de cultivares de cebola nos sistemas orgânicos e convencional em Minas Gerais. Horticultura Brasileira 24: 206-209.

VIDIGAL SM; SEDIYAMA MAN; PEDROSA MW; SANTOS MR. 2010. Produtividade de cebola em cultivo orgânico utilizando composto à base de dejetos de suínos. Horticultura Brasileira 28: 168-173.

WORDELL FILHO JA; ROWE E; GONÇALVES PAS; DEBARBAJF; BOFF P; THOMAZELLI LF. 2006. Manejo fitossanitario na cultura da cebola. Florianópolis: Epagri. 226p. 